\title{
Prone and left lateral positioning reduce gastro-oesophageal reflux in preterm infants
}

\author{
A K Ewer, $M$ E James, J M Tobin
}

\begin{abstract}
Aim-To examine the effect of body position on clinically significant gastrooesophageal reflux (GOR) in preterm infants.

Methods-Eighteen preterm infants with clinically significant GOR were studied prospectively using 24 hour lower oesophageal pH monitoring. Infants were nursed in three positions (prone, left, and right lateral) for 8 hours in each position, with the order randomly assigned. Data were analysed using analysis of covariance.

Results-The median (range) reflux index (RI) for the group was $13.8 \%(5.8-40.4)$. There was no significant difference in the mean time spent in each position. RI (mean \% (SEM)) was significantly less in prone (6.3 (1.7)) and left lateral positions (11.0 (2.2)), when compared with the right lateral position $(29.4(3.2)) ; p<0.001$. The mean (SEM) longest episodes (mins) of GOR were reduced by prone and left positions (8.6 (2.2) and 10.0 (2.4), respectively) compared with the right position (26.0 (3.9)); $\mathbf{p}<0.001$. The mean (SE) number of episodes was reduced by prone $(15.4(2.8))$ and left (24.6 (3.5)) positions when compared with right $(41.6(4.6))(\mathrm{p}<0.001)$.

Conclusions-Prone and left lateral positions significantly reduce the severity of GOR, by reducing the number of episodes and the duration of the longest episodes. Such positioning offers a useful adjunct to the treatment in hospital of preterm infants with gastro-oesophageal reflux.
\end{abstract} (Arch Dis Child Fetal Neonatal Ed 1999;81:F201-F205)

Keywords: preterm; gastro-oesophageal reflux; body position

Neonatal Unit Birmingham Women's Hospital

Edgbaston

Birmingham

B15 2TG

A K Ewer

M E James

Institute of Child

Health

University of

Birmingham

A K Ewer

J M Tobin

Correspondence to:

Dr Andrew Ewer

Email: a.k.ewer@bham.ac.uk

Accepted 26 May 1999 increased abdominal pressure which makes reflux worse $\mathrm{w}^{58}$ and use of this mode of treatment has declined.

Prone positioning can reduce the degree of reflux. ${ }^{9-11}$ The supine position predisposes to a greater degree of reflux than the prone position. ${ }^{912}$ The benefits of nursing on a slope are less clear. ${ }^{13} 14$

Concern about the association between prone positioning and increased risk of sudden infant death syndrome (SIDS) ${ }^{15} 16$ stimulated work on the effect of lateral positioning on the degree of GOR in term infants. In this group the prone and left lateral positions were both associated with significantly less reflux compared with the right lateral and supine positions. ${ }^{14}$

The effect of body position on GOR in preterm infants is not clear. In a study of 35 preterm infants Newell noted that the prone and right lateral positions exhibited similar degrees of reflux whereas the left lateral position showed a non-significant trend towards greater severity of reflux. ${ }^{1}$ However, the study was not specifically designed to examine this effect and the time actually spent in each position is not clear.

As far as we are aware, no study has specifically examined the effect of body position on the severity of GOR in preterm infants.

This study therefore aimed to evaluate prospectively the severity of reflux parameters in each of the three common nursing positions for preterm infants in hospital. The supine position was not examined as this seems to be unequivocally associated with more severe reflux and apnoea. ${ }^{9} 1217$

\section{Methods}

The study was carried out on the Regional Neonatal Intensive Care Unit at Birmingham Women's Hospital. The effect of body position on clinically significant reflux was of interest, so only infants who were suspected clinically of having GOR were enrolled. The clinician in charge requested a 24 hour $\mathrm{pH}$ study as a routine investigation. Infants were then enrolled if they fulfilled the following criteria: preterm delivery (less than 37 weeks of gestation); more than 7 days old; receiving full enteral feeds at a minimum of $150 \mathrm{ml} / \mathrm{kg} /$ day. Symptoms in those enrolled included excessive regurgitation of feeds and xanthine resistant apnoea and bradycardia (where infection had been excluded).

Thirty infants were initially enrolled into the study. Twelve were excluded for the following reasons: two did not complete the study because of clinical deterioration which required discontinuation of feeds; five infants did 
not have clinically significant reflux, having a reflux index less than 5\%; and in five infants, either the infant was not nursed in one of the three positions for clinical reasons, or position documentation was unsatisfactory and the time spent in each position was impossible to calculate accurately. The remaining 18 infants comprised 12 boys and six girls with a median (range) gestation of 28 (25-32) weeks, birthweight $945(480-1750)$ g, and age at study 27 (11-73) days.

There was no significant difference in gestation, birthweight, or age at time of study between those infants included and those excluded ( $\mathrm{n}=12)$ (Mann-Whitney U test).

Of the 18 study infants, 10 were fed expressed maternal breast milk, three fed fortified breast milk, three fed preterm formula (Cow and Gate Nutriprem), three a combination of fortified breast milk and Nutriprem; one was fed term formula (Cow and Gate Premium), and one Pregestimil (Bristol-Myers). All infants were fed via an indwelling nasogastric tube at intervals ranging from one to three hours. Fourteen infants received hourly feeds, one infant received two hourly feeds, and three infants three hourly feeds.

Eleven of the study infants were receiving drugs which have been reported to affect GOR: seven infants were receiving caffeine, two were receiving cisapride, and two infants were receiving both of these drugs. These drugs were continued during the study period according to our clinical practice. This did not affect the results as each infant was its own control.

LOWER OESOPHAGEAL $\mathrm{pH}$ MONITORING

The intra-oesophageal $\mathrm{pH}$ monitoring system used a $1.5 \mathrm{~mm}$ diameter monocrystalline antimony $\mathrm{pH}$ electrode and Digitrapper Mk III solid state recorder (Synectics Medical Ltd, Sweden) over a 24 hour period. The position of the lower oesophageal sphincter was estimated by measuring the distance from the shoulder tip to the umbilicus. The $\mathrm{pH}$ electrode was then passed nasally into the oesophagus and positioned at $7 / 8$ of this distance. Position of the electrode tip was confirmed by chest $x$-ray and was judged satisfactory if it was $1 \mathrm{~cm}$ above the diaphragm. Calibration of the $\mathrm{pH}$ electrode was performed before and after each study using standard buffer solutions of $\mathrm{pH} 1.07$ and 7.01 (Synectics Medical Ltd, Sweden). No drift was noted.

At the beginning of the study period each infant was randomly assigned by sealed envelope to one of the six permutations of the three nursing positions (right, left, prone; prone, left, right, etc) and the infant was successively nursed in each of these positions for periods of 8 hours (or as near as possible) during the study. The right and left positions were lateral positions with the stated side lowermost. Position was not altered during or immediately after feeds. Nurses kept a hand written diary of positioning and any significant events such as handling and feeding.

Infants remained in the study if they then fulfilled the following criteria: a reflux index of $5 \%$ or greater; a technically satisfactory study; all time accounted for with a completed diary of nursing observations and correct rotation through the prescribed position order.

We chose a reflux index of $5 \%$ as our clinical experience suggests that symptoms can occur at this level.

Informed parental consent was obtained in each case and the protocol was approved by the local research ethics committee.

\section{DATA ANALYSIS}

Position data from the study infants were then analysed using the EsopHogram computer software package (Gastrosoft Inc., Synectics Medical Ltd, Sweden). Parameters of reflux severity (RI), number of reflux episodes, number of episodes greater than 5 minutes, and duration of longest episode) were then analysed in each of the three positions to assess the effect of position on severity of GOR. A reflux episode was defined as a lower oesophageal $\mathrm{pH}$ of $<4.0$ for 15 seconds or longer. RI was defined as the percentage of study time during which lower oesophageal $\mathrm{pH}$ was $<4.0$.

The study contained a treatment factor (position). The order of positions was randomised into the six possible permutations of the three 8 hour position segments. The reflux parameters in each of those positions were analysed using analysis of covariance (ANCOVA). The actual time each infant spent in each of the three positions was analysed as the covariate in the ANCOVA to allow for the fact that time spent in each position may affect the reflux parameters. The analysis additionally contained two other sources of variation: between infant and between 8 hour period within days.

The assumptions of the ANCOVA were assessed graphically. The residuals did not fit a normal distribution with the error variance increasing with increasing values. Thus a square root transformation (for number of episodes, number of episodes greater than 5 minutes, and longest episode) and an arcsine transformation (for RI) were applied to stabilise the variance and the assumptions then held. To retain the familiar scale of measurement, the treatment means and standard errors were adjusted for the covariate-the actual time in each position in the ANCOVA and then transformed back appropriately to the original scale. Pairwise comparison of means were done with the least significant difference (LSD) method at the 5\% level to evaluate the differences between positions.

All statistical analyses were performed using Minitab for Windows statistical software.

\section{Results}

The median (range) reflux parameters for the 18 infants over the 24 hour study period are shown in table 1 .

Table 2 shows the predicted mean (SEM) reflux parameters for each of the three nursing positions. There were no significant differences in the mean times spent in each of the three positions.

For reflux index, the effect of position was highly significant $(\mathrm{p}<0.001)$. Prone position 
Table 1 Median (range) reflux parameters for the 24 hour study period $(n=18)$

\begin{tabular}{lll}
\hline Reflux parameter & Median & Range \\
\hline Reflux index (\%) & 13.8 & $5.8-40.4$ \\
No of episodes & 80 & $29-243$ \\
No $>5$ minutes & 8 & $3-25$ \\
Longest episode (min) & 28 & $15-70$ \\
\hline
\end{tabular}

Table 2 Predicted mean (SEM) reflux parameters in the three nursing positions after covariance adjustments

\begin{tabular}{llll}
\hline & Prone & Left & Right \\
\hline Time (min) & $480(9.3)$ & $485(10.6)$ & $470(7.3)$ \\
Reflux index (\%) & $6.3(1.7)$ & $11.0(2.2)$ & $29.4(3.2)^{\star}$ \\
No of episodes & $15.4(2.8)$ & $24.6(3.5)$ & $41.6(4.6)^{\star}$ \\
Episodes $>5$ min & $1.1(0.4)$ & $1.8(0.5)$ & $4.5(0.8)^{\star \star}$ \\
Longest episode & $8.6(2.2)$ & $10.0(2.4)$ & $26.0(3.9)^{\star}$ \\
\hline
\end{tabular}

$\left({ }^{\star} \mathrm{p}<0.001,{ }^{\star \star} \mathrm{p}=0.002\right)$. Time means are for raw data

was significantly less than left, and both were significantly less than right position.

For number of reflux episodes, the effect of position was again highly significant $(p<0.001)$. Prone position was significantly less than left, and both were significantly less than right position.

For number of episodes $>5$ minutes and duration of longest episode, the effect of position was significant $(p=0.002$ and $\mathrm{p}<0.001$, respectively). Both prone and left positions were significantly less than right (fig $1)$.

\section{Discussion}

This study shows the effect of body position on the severity of GOR. Examining all the reflux parameters - the total number of reflux episodes, reflux episodes with a duration greater than five minutes, the longest reflux episode and the reflux index - there is an obvious trend

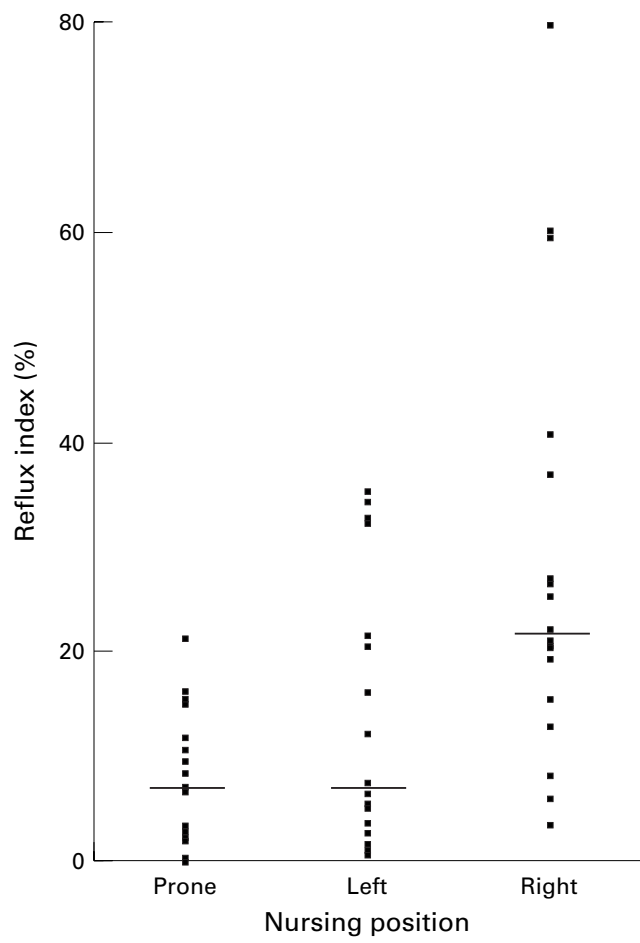

Figure 1 Raw reflux index data for each nursing position (horizontal line indicates median value) from the lowest values in the prone nursing position to the highest values in the right lateral position. Therefore, most acid reflux occurred while the infant was in the right lateral position, with the left lateral position showing a significant reduction in all reflux parameters compared with the right. Indeed, the left lateral position was just as effective as the prone position at reducing the length of the longest reflux episode, with both virtually halving the mean longest episode.

This effect is similar to that seen in term infants, where the major benefit for position was a reduction in duration of episodes. These findings have not been described before in preterm infants. The results are not invalidated by the infants who were receiving medication affecting reflux, as each was their own control and the same association was clearly seen in these infants. The infants were also out of the prescribed position for very brief periods during their allocated time. This contrasts to the term infant study ${ }^{14}$ where many data were lost during time spent out of position. The greater severity of reflux in the preterm infants (with a median RI of around 14\%) compared with the term infant study (where it was around $10 \%$ ), has clarified the dramatic benefits of positioning for the refluxing infant. The effect is seen across all reflux parameters including measures of both frequency and duration, rather than the predominant duration effect seen in the term infants. ${ }^{14}$

GOR can be a serious problem for preterm infants. It is a potent cause of apnoea in this group and may contribute to chronic lung disease by recurrent aspiration of milk/gastric contents. Symptoms of reflux may also delay or prevent successful enteral feeds and this in turn may have adverse effects on growth and subsequent neurodevelopmental outcome. ${ }^{18}$

Until recently the prokinetic agent cisapride has been successfully used to treat GOR in preterm infants. ${ }^{19}{ }^{20}$ However, concerns about prolongation of $\mathrm{QT}_{\mathrm{c}}$ interval and cardiac arrhythmias, particularly in infants under 3 months of age, ${ }^{21}$ has led to discontinuation of its use in these patients.

The identification of a non-pharmacological treatment which reduces the severity of GOR in this group-position-therefore has important implications for the management of these infants. In addition, the beneficial effect of left sided positioning is extremely helpful as continuous nursing in the prone position may lead to postural deformities particularly of the hips, ${ }^{22}$ and sleeping in the prone position has been associated with sudden infant death. ${ }^{15} 16$

Why should the prone and left lateral positions seem to protect against reflux when compared with the supine and right lateral positions? The effect is likely to be related to the anatomical configuration of the stomach and gastro-oesophageal junction. Previous work has shown that the mechanism of GOR in preterm infants may be a consequence of inappropriate relaxation of the lower-oesophageal sphincter (LOS) and immature oesophageal peristalsis. ${ }^{23}{ }^{24}$ These phenomena may lead to regurgitation of gastric contents into the lower 


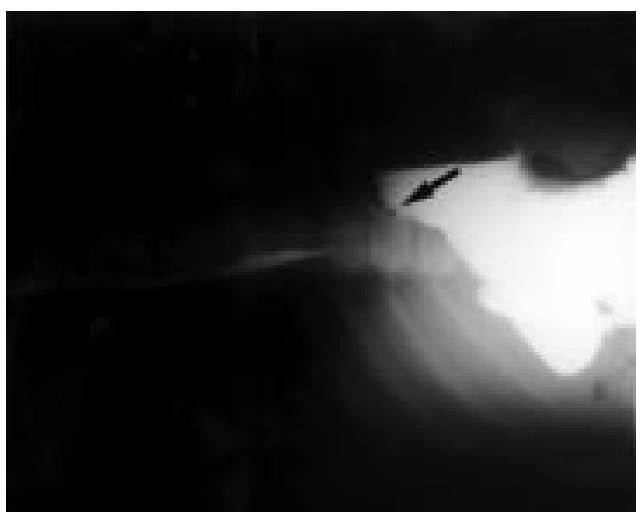

Figure 2 Antero-posterior radiograph of a barium swallow in a mature infant lying in the right lateral position. Even thought the stomach is not full, the gastro-oesophageal junction (arrowed) is submerged beneath the air-fluid level in the gastric fundus.

oesophagus and poor clearance of refluxed material, respectively. The former is more likely to occur if the stomach contents abut the LOS: the LOS is posteriorly positioned relative to the rest of the stomach so this is more likely to occur with the infant supine. In the prone position the gastric contents are likely to settle in the body and antrum of the stomach away from the LOS. In the lateral positions the gastric contents will settle either in the antrum and lesser curvature of the stomach (right lateral) (fig 2) or the body and greater curvature (left lateral) (fig 3). The body of the stomach may offer a greater reservoir volume which keeps the level of gastric contents away from the LOS. The pressure from the gastric contents on the gastro-oesophageal angle when in the left lateral position may also improve LOS pressure, thus reducing the tendency of the sphincter to relax.

The effect of body position on gastric emptying in preterm infants is uncertain. Yu indicated that gastric emptying may be delayed in the left lateral and supine positions, ${ }^{25}$ although a different group found no difference between position and gastric emptying. ${ }^{26} \mathrm{How}-$ ever, previous studies in preterm infants have

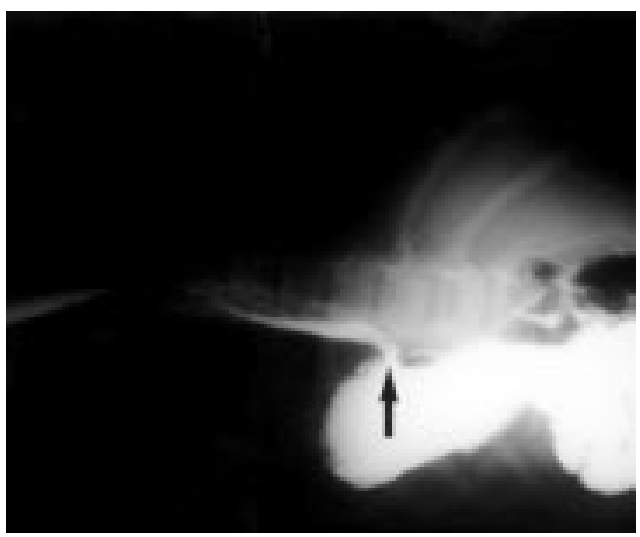

Figure 3 Posterio-anterior radiograph of a barium swallow in a mature infant lying in the left lateral position. The reservoir function of the body of the stomach, keeping the gastric contents below the level of the gastro-oesophageal junction (arrowed), is shown. NB: barium is present in the oesophagus in both films. The infants swallowed barium to delineate the oesophagus; these images do not represent reflux episodes. shown that gastric emptying is unrelated to the incidence and severity of GOR, ${ }^{2}$ so the effect of position on gastric emptying is likely to be unimportant.

An interesting observation in this study was the potential effect of drugs on the severity of GOR. Two drugs which may affect GOR are cisapride and caffeine. Cisapride can reduce GOR in older infants ${ }^{27}$ and has been widely used in preterm infants. ${ }^{19}$ Two infants in the study group were receiving cisapride as a treatment for suspected reflux. It is our practice on the neonatal unit to continue any medication begun before the $\mathrm{pH}$ study (with the exception of ranitidine). Interestingly, the mean reflux parameters of the subjects receiving cisapride were the lowest in the study group, although the numbers are small. Conversely, xanthines such as caffeine are known to stimulate gastric acid production and reduce LOS pressure ${ }^{28} 29$ and xanthine resistant apnoeas have been described in preterm infants. ${ }^{1}$ The seven subjects in this study who were receiving caffeine had the highest mean reflux parameters. The two subjects who were receiving both caffeine and cisapride and the seven subjects receiving no drug treatment had reflux parameters between these two extremes. A larger study to investigate the effect of xanthines on the severity of GOR in preterm infants would be interesting as studies in term infants on xanthines show reflux is increased by around $50 \% .^{29}$ Clearly, the study was not designed to examine these effects but they are noteworthy as it may be prudent to stop caffeine in an infant showing continuing resistant apnoea with demonstrable reflux.

The left lateral position can now be adopted in addition to prone for refluxing premature infants and while they are in hospital nursing position can be alternated between the two. Our data suggest that a reduction in reflux index of at least one third will be observed if right sided positioning is avoided. These data are also of importance when advising parents of preterm infants with GOR about sleeping position after discharge from hospital. Parents can now avoid the prone position, but still have the significant clinical benefit of the left sided position.

We are grateful to Dr Paul Davies for his invaluable statistical advice and to the medical and nursing staff on the neonatal unit at Birmingham Women's Hospital for their co-operation with this study. This work was presented in part to the 2 nd Annual Meeting of the Royal College of Paediatrics and Child Health, York, April 1998.

1 Newell SJ, Booth IW, Morgan MEI, Durbin GM, McNeish AS. Gastro-oesophageal reflux in preterm infants. Arch Dis Child 1989;64:780-6.

2 Ewer AK, Durbin GM, Morgan MEI , Booth IW. Gastric emptying and gastro- oesophageal reflux in preterm infants. Arch Dis Child Fetal Neonatal Ed 1996;75:F11721

3 Wharton BA, Bower BD. Immediate or later feeding for premature babies? Lancet 1965;ii:969-72.

4 Herbst JJ, Minton SD, Book LS. Gastro-oesophageal reflux causing respiratory distress and apnoea in newborn infants. F Pediatr 1979;95:763-8.

5 Carré IJ. The management of gastro-oesophageal reflux. Arch Dis Child 1985;60:71-75.

6 Meyers WF, Herbst JJ. Effectiveness of positioning therapy for gastro-oesophageal reflux. Pediatrics 1982;69:768-72.

7 Dodds WJ, Dent J, Hogan WJ, et al. Mechanisms of gastrooesophageal reflux in patients with reflux oesophagitis. $N$
Engl F Med 1982;307:1547-52. 
8 Orenstein SR, Whitington PF. Positioning for prevention of gastro-oesophageal reflux. F Pediatr 1983;103:534-7.

9 Blumenthal I, Lealman GT. Effect of posture on gastrooesophageal reflux in the newborn. Arch Dis Child 1982;57:555-6.

10 Vandenplas Y, Sacre-Smits L. Seventeen-hour continuous oesophageal monitoring in the newborn: evaluation of the influence of position in asymptomatic and symptomatic babies. F Pediatr Gastroenterol Nutr 1985;4:356-61.

11 Tam P, Lin LH. Fifteen-hour continuous oesophageal $\mathrm{pH}$ monitoring: influence of position on gastro-oesophageal reflux among asymptomatic babies. Acta Paediatr Sin 1993;34:14-21.

12 Ramenovsky ML, Leape LL. Continuous upper oesophageal $\mathrm{pH}$ monitoring in infants and children with gastro-oesophageal reflux, pneumonia and apneic spells. $\mathcal{F}$ Pediatr Surg 1981;16:374-8.

13 Orenstein SR. Prone positioning in infant gastrooesophageal reflux: is elevation of the head worth the trouoesophageal reflux: is elevation
ble? f Pediatr 1991;117:184-7.

14 Tobin JM, McCloud P, Cameron DJS. Posture and gastro-oesophageal reflux: a case for left lateral positiongastro-oesophageal reflux: a case for

15 Dwyer T, Ponsonby AB, Newman NM, Gibbons LE. Prospective Prospective cohort study of prone sleeping position and

16 Beal S. Sudden infant death syndrome related to sleeping position and bedding. Med F Aust 1991;155:507-8.

17 Kurlak LO, Ruggins NR, Stephenson TJ. Effect of nursing position on incidence, type and duration of clinically significant apnoea in preterm infants. Arch Dis Child Fetal Neonatal Ed 1994;71: F16-19.

18 Georgieff MK, Hoffman JS, Pereira GR, Bernbaum J, Hoffman-Williamson $M$. Effect of neonatal caloric deprivation on head growth and 1-year developmental status in preterm infants. F Pediatr 1985;107:581-7.
19 Melis K, Janssens G. Long-term use of cisapride (Prepulsid) in premature neonates. Acta Gastroenterologica Belgica 1990;53:372-5.

20 Janssens G, Melis K, Varenberg M. Long term use of cisapride (Prepulsid) in premature neonates of less than 34 weeks gestational age. 7 Pediatr Gastroenterol Nutr 1990;11:420-5.

21 Bernardini S, Semama DS, Huet F, Sgro C, Gouyon JB. Effects of cisapride on QTc interval in neonates. Arch Dis Child Fetal Neonatal Ed 1997;77:F241-3.

22 Downs JA, Edwards AD, McCormick DC, Roth SC, Stewart AL. Effect of intervention on development of hip posture in very preterm babies. Arch Dis Child 1991;66:797801.

23 Omari TI, Miki K, Fraser R, et al. Oesophageal body and lower oesophageal sphincter function in healthy preterm infants. Gastroenterology 1995;109:1757-64.

24 Omari TI, Miki K, Davidson G, et al. Characterisation of relaxation of the lower oesophageal sphincter in healthy premature infants. Gut 1997;40:370-5.

$25 \mathrm{Yu}$ VYH. Effect of body position on gastric emptying in the neonate. Arch Dis Child 1975;50:500-4

26 Blumenthal I, Ebel A, Pildes RS. Effect of posture on the pattern of stomach emptying in the newborn. Pediatrics 1979;63:532-6.

27 Cucchiara S, Staiano A, Boccieri A, et al. Effects of cisapride on parameters of oesophageal motility and on the
prolonged intra-oesophageal pH test in infants with prolonged intra-oesophageal $\mathrm{pH}$ test in infants
gastro-oesophageal reflux disease. Gut 1990;31:21-5.

28 Dennish GW, Castell DO. Caffeine and the lower oesophageal sphincter. Am f Dig Dis Sci 1972;17:993-6.

29 Vandenplas Y, De Wolf D, Sacre L. Influence of xanthines on gastro-oesophageal reflux in infants at risk for sudden infant death syndrome. Pediatrics 1986;77:807-10. 